\title{
Effect of betamethasone and betamethasone with neomycin nasal drops on human nasal mucociliary clearance and ciliary beat frequency
}

\author{
PJ STANLEY, WM GRIFFIN, R WILSON, MA GREENSTONE, IS MACKAY, PJ COLE \\ From the Host Defence Unit, Department of Medicine, Cardiothoracic Institute, and Nose Clinic, Brompton \\ Hospital, London
}

\begin{abstract}
The effects of two topical nasal preparations on human nasal ciliary beat frequency in vitro and on nasal mucociliary clearance in vivo were investigated. Betamethasone and betamethasone with neomycin drops were found to be ciliotoxic when ciliated epithelium was exposed to them in vitro, mainly owing to the effects of the preservatives benzalkonium chloride and thiomersal. The nasal mucociliary clearance and in vitro ciliary beat frequency of nasal ciliated epithelium taken from healthy subjects were not adversely affected after topical application; neither did treatment with betamethasone, with or without neomycin, for four weeks affect these indices in two groups of patients with rhinitis. Thus, despite a ciliotoxic effect when ciliated epithelium is exposed to these preparations in vitro, they do not affect nasal clearance or ciliary beat frequency (as measured in vitro) adversely when administered topically to the nose.
\end{abstract}

Mucociliary clearance is a major element of the defence system of the whole respiratory tract, potentially noxious substances trapped in the mucus blanket being removed by the coordinated beat of the cilia. Reduction of mucociliary clearance, whether primary or secondary, may allow potentially harmful material such as microorganisms or allergens to remain in contact with the epithelium, causing or exacerbating existing disease. Severely disordered mucociliary clearance in patients with primary ciliary dyskinesia leads to chronic infections of both the upper and the lower respiratory tracts.

Various preservatives in topical medications were shown by van de Donk and coworkers to be ciliotoxic to animal cilia in vitro.' ${ }^{1}$ They reported a similar toxic effect on human adenoidal cilia $^{2}$ and also a slowing of nasal mucociliary clearance after administration of benzalkonium chloride with ethylenediamine-tetra-acetic acid (EDTA). ${ }^{3}$ Nasal mucociliary clearance is prolonged in rhinitis ${ }^{4}$ and further impairment due to therapy would be undesirable.

This study examined the effects of betamethasone

Address for reprint requests: Dr PJ Stanley, Cardiothoracic Institute, Brompton Hospital, London SW3 6HP.

Accepted 19 March 1985 nose drops (Betnesol, Glaxo) and betamethasone with neomycin drops (Betnesol- $\mathrm{N}$, Glaxo) on human nasal cilia in vitro and on nasal mucociliary clearance after acute and long term use.

\section{Methods}

IN VITRO EXPERIMENTS

Ciliated epithelium from the inferior nasal turbinates of five healthy normal volunteers was obtained by a brushing technique not requiring local anaesthesia, ${ }^{5}$ and added to vials containing $2 \mathrm{ml}$ aliquots of either tissue culture medium 199 (Flow Laboratories) alone or test drug or other substance dissolved in this medium. Each specimen was transferred to a sealed microscope slide preparation kept at $37^{\circ} \mathrm{C}$ on a warm stage and viewed under a microscope. At least six strips of epithelium were identified and their position on the slide was marked. The ciliary beat frequency of 10 randomly selected areas of beating cilia from all these strips was measured by a photometric technique ${ }^{5}$ at varying times from five to 360 minutes by an observer unaware of the nature or concentration of the drug or other substance being tested. Ciliostasis was recorded if no ciliary motion was visible throughout the epithelial strips. The ciliary beat frequency was calculated as the mean of the 10 readings and ex- 
pressed as a percentage of the value for the control readings (medium 199 alone).

The following substances were tested at varying concentrations: betamethasone nose drops and betamethasone with neomycin nose drops reconstituted from pure ingredients, and the individual constituents betamethasone, neomycin, benzalkonium chloride, EDTA, and thiomersal. The betamethasone nose drops contained betamethasone sodium phosphate $1.0 \mathrm{mg} / \mathrm{ml}$; benzalkonium chloride $200 \mu \mathrm{g} / \mathrm{ml}$; EDTA $100 \mu \mathrm{g} / \mathrm{ml}$. The betamethasone with neomycin nose drops contained betamethasone sodium phosphate $1.0 \mathrm{mg} / \mathrm{ml}$; neomycin $5.0 \mathrm{mg} / \mathrm{ml}$; thiomersal $50 \mu \mathrm{g} / \mathrm{ml}$.

Cilia from each of the five subjects were examined at each drug concentration and time point, and the overall ciliary beat frequency results calculated as a mean of these five experiments. All drug solutions were verified to have a $\mathrm{pH}$ of 6.8-7.2.

To investigate the reversibility of any toxic effect, cilia exposed to betamethasone and to betamethasone with neomycin drops were resuspended in fresh medium 199 after gentle centrifugation (186 $\boldsymbol{g}$ for 10 minutes). In addition, an experiment using benzalkonium chloride with EDTA was performed at $25^{\circ} \mathrm{C}$ so that any effect of temperature on results could be demonstrated. The action of the chelating agent EDTA was further investigated by using Dulbecco A phosphate buffered saline (Oxoid Ltd), which is free of calcium and magnesium, in place of medium 199.

IN VIVO EXPERIMENTS

Acute effect of betamethasone drops on nasal mucociliary clearance and ciliary beat frequency

The subjects were six healthy volunteers with no history of chronic respiratory disease and no recent acute upper respiratory infection. Nasal mucociliary clearance was measured in one nostril by a saccharin technique ${ }^{6}$ as modified by Rutland and Cole. ${ }^{7}$ After clearing the nose by gentle blowing a $1 \mathrm{~mm}$ diameter particle of saccharin was placed $1 \mathrm{~cm}$ from the anterior end of the inferior nasal turbinate and the time elapsing before the subject first experienced a sweet taste was recorded. This test has been shown to be reproducible in a subject tested on different occasions. ${ }^{8}$ Nasal ciliary beat frequency was measured from ciliated epithelium obtained by brushing the contralateral inferior turbinate, as described above. After an interval of about four hours, designed to allow the sweet taste to dissipate, three betamethasone nose drops were instilled on to the inferior turbinate of each nostril with a syringe and cannula. The nasal mucociliary clearance and ciliary beat frequency measurements were repeated 15 minutes later.
All nasal mucociliary clearance results are expressed as means (time in minutes) with standard deviations in parentheses.

\section{Long term effects of betamethasone and betamethasone with neomycin drops on nasal mucociliary clearance}

Nasal mucociliary clearance was measured by the saccharin technique as before in two groups of patients before and after treatment with two drops instilled in each nostril twice daily for one month. The betamethasone treated group consisted of 36 patients with perennial non-allergic rhinitis (longer than 12 months' history of watery rhinorrhoea, nasal obstruction, and sneezing with no history of allergy, negative skinprick test responses to common allergens, and normal serum IgE). The group treated with betamethasone with neomycin consisted of 40 patients suffering from chronic rhinosinusitis with infection (longer than six months' history of mucopurulent rhinorrhoea or postnasal discharge and abnormal sinus radiographs).

No patient was having any topical nasal treatment when initially tested and nasal mucociliary clearance was measured in the same nostril before and after treatment. The last dose of drops was six to eight hours before the second clearance measurement. Clinical response to treatment was also documented.

\section{Results}

\section{IN VITRO EXPERIMENTS}

The results observed with betamethasone and betamethasone with neomycin drops at the concentration found in the commercial preparations and with dilutions to $1: 50$ are shown in figures 1 and 2 .

Betamethasone drops in a dilution of $1: 2$ caused ciliostasis within five minutes and $1: 10$ caused ciliostasis in 90 minutes. At 1:25 dilution the mean ciliary beat frequency after 360 minutes was $68 \%$ (9.1\%) of control (medium 199 alone) values. No difference from control was seen at a dilution of 1:50. Betamethasone with neomycin drops caused ciliostasis within five minutes in a dilution of $1: 2$, but after 180 and 360 minutes at $1: 10$ and $1: 25$ respectively. There was no difference from control time at 1:50 dilution. After ciliostasis had occurred it was observed that there was considerable distortion of cellular architecture and there was no reversal of the effect after resuspension of the epithelium in fresh medium 199.

When the individual constituents of the drops were used, betamethasone and EDTA had no significant effect on cilia at concentrations of up to 4 $\mathrm{mg} / \mathrm{ml}$ and $1 \mathrm{mg} / \mathrm{ml}$ respectively - that is, at considerably higher concentrations than are found in the 


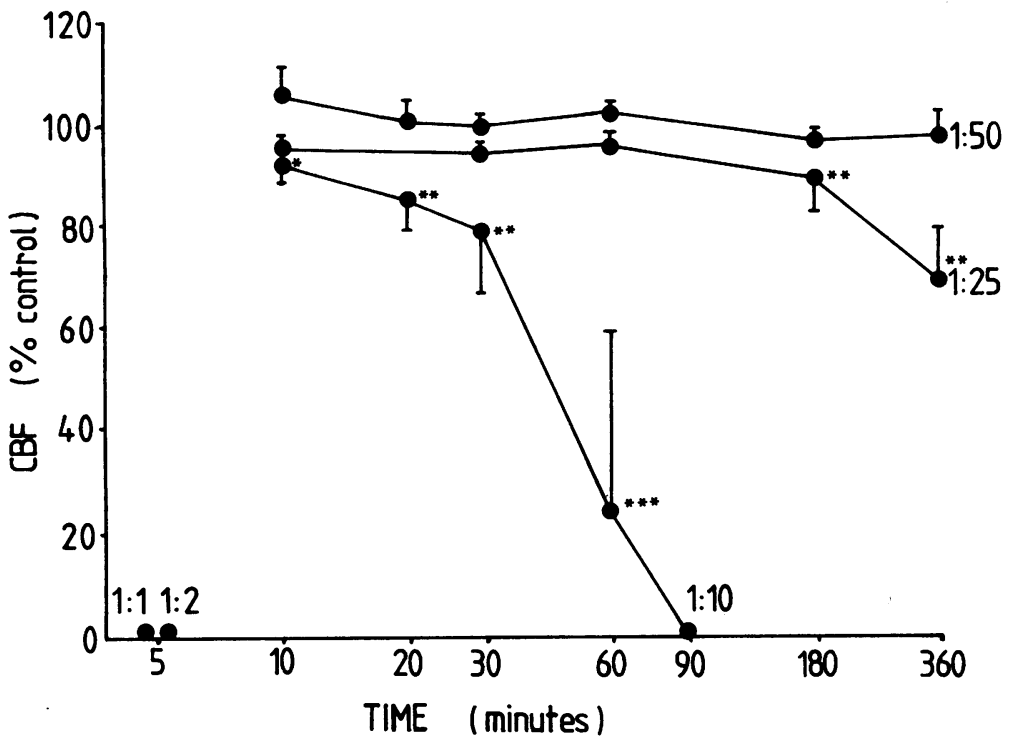

Fig 1 Effect of betamethasone nose drops, reconstituted from pure ingredients, on human nasal ciliary beat frequency $(C B F)$. Mean of five experiments with standard deviation. The ratio by each curve represents the dilution in medium 199. Time is expressed on a log scale. ${ }^{*} p<$ $0.05,{ }^{* *} p<0.01,{ }^{* * *} p<0.001$ with reference to control values (Student's $t$ test).

drop preparations. When calcium free phosphate buffered saline was used instead of medium 199, again EDTA $1 \mathrm{mg} / \mathrm{ml}$ did not significantly affect ciliary beat frequency. Neomycin produced a significant reduction of mean ciliary beat frequency-to $82 \%$ $(5.7 \%)$ of the control value-after 360 minutes at a concentration of $5 \mathrm{mg} / \mathrm{ml}$.

Benzalkonium chloride and thiomersal, however, produced patterns of ciliostasis similar to those of the reconstituted drops (figs 3 and 4). Benzalkonium chloride at concentrations of 200 and $100 \mu \mathrm{g} / \mathrm{ml}$ caused ciliostasis within five minutes and at $20 \mu \mathrm{g} / \mathrm{ml}$ after 60 minutes, and at $8 \mu \mathrm{g} / \mathrm{ml}$ ciliary beat frequency was $57 \%(10.0 \%)$ of control after 360 minutes. Thiomersal caused ciliostasis within five minutes at $25 \mu \mathrm{g} / \mathrm{ml}$, in 180 minutes at $5 \mu \mathrm{g} / \mathrm{ml}$, and in 360 minutes at $2 \mu \mathrm{g} / \mathrm{ml}$. After 360 minutes benzalkonium chloride $5 \mu \mathrm{g} / \mathrm{ml}$ had no significant effect on ciliary beat frequency, while thiomersal $1 \mu \mathrm{g} / \mathrm{ml}$ produced a slight but significant effect.

Addition of $1 \mathrm{mg} / \mathrm{ml}$ EDTA to $20 \mu \mathrm{g} / \mathrm{ml} \mathrm{benz-}$ alkonium chloride initially caused more depression

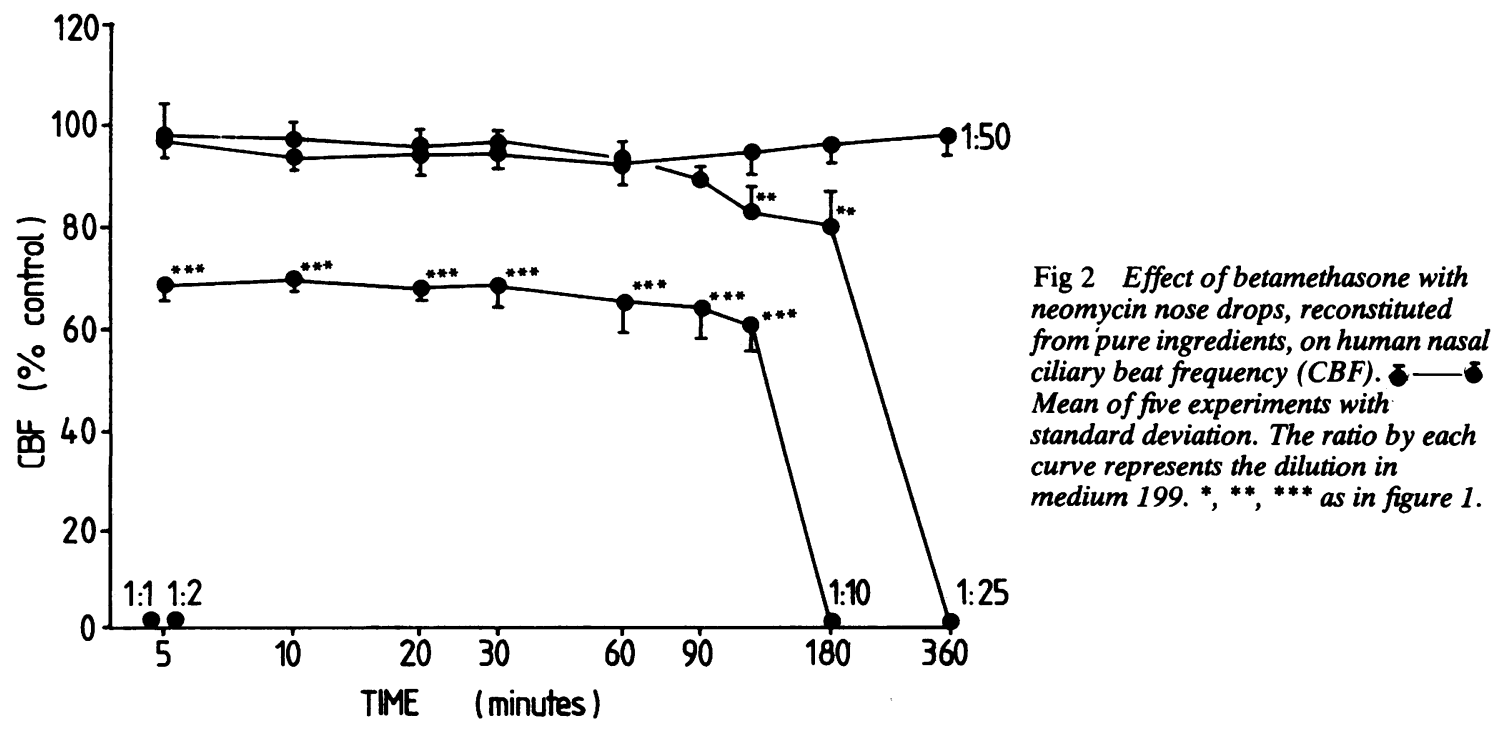




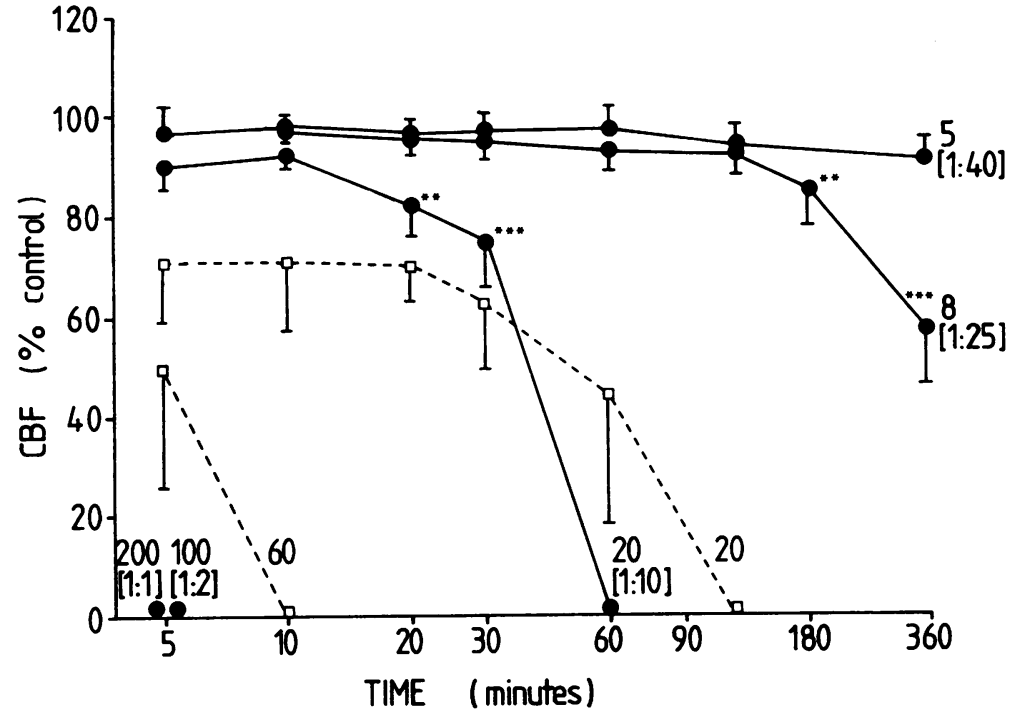

Fig 3 Effect of benzalkonium chloride and benzalkonium chloride with ethylenediamine-tetra-acetic acid (EDTA) on human nasal ciliary beat frequency $(C B F) . ర$ Mean of five experiments with standard deviation, benzalkonium chloride used alone; 0 Mean of five experiments with $S D$, benzalkonium chloride used with EDTA $1 \mathrm{mg} / \mathrm{ml}$. The number beside each curve represents the concentration of benzalkonium chloride in $\mu \mathrm{g} / \mathrm{ml}$ with the equivalent dilution found in the commercial preparation in brackets. *, ${ }^{* *},{ }^{* * *}$ as in figure 1 .

of ciliary beat frequency than did $20 \mu \mathrm{g} / \mathrm{ml}$ benzalkonium chloride alone, but complete ciliostasis occurred only after 120 minutes compared with 60 minutes without EDTA (fig 3). Benzalkonium chloride $60 \mu \mathrm{g} / \mathrm{ml}$ with EDTA $1 \mathrm{mg} / \mathrm{ml}$ caused a reduction in ciliary beat frequency to $50 \%(28.4 \%)$ of the control value after five minutes and complete ciliostasis after 10 minutes. At $25^{\circ} \mathrm{C}$, however, the reduction in ciliary beat frequency was less, being $79 \%(15.0 \%)$ of control after five minutes and $53 \%(7.0 \%)$ after 30 minutes.
IN VIVO EXPERIMENTS

Acute effect of betamethasone drops on nasal mucociliary clearance and ciliary beat frequency Before treatment mean nasal mucociliary clearance time was 17.3 (6.2) minutes and mean nasal ciliary beat frequency was $13.0(0.6) \mathrm{Hz}$. Fifteen minutes after administration of three drops of betamethasone nose drops nasal mucociliary clearance and ciliary beat frequency had not changed significantly $(12.7(6.0)$ minutes and $13.0(0.8) \mathrm{Hz}$; Mann-Whitney U test).

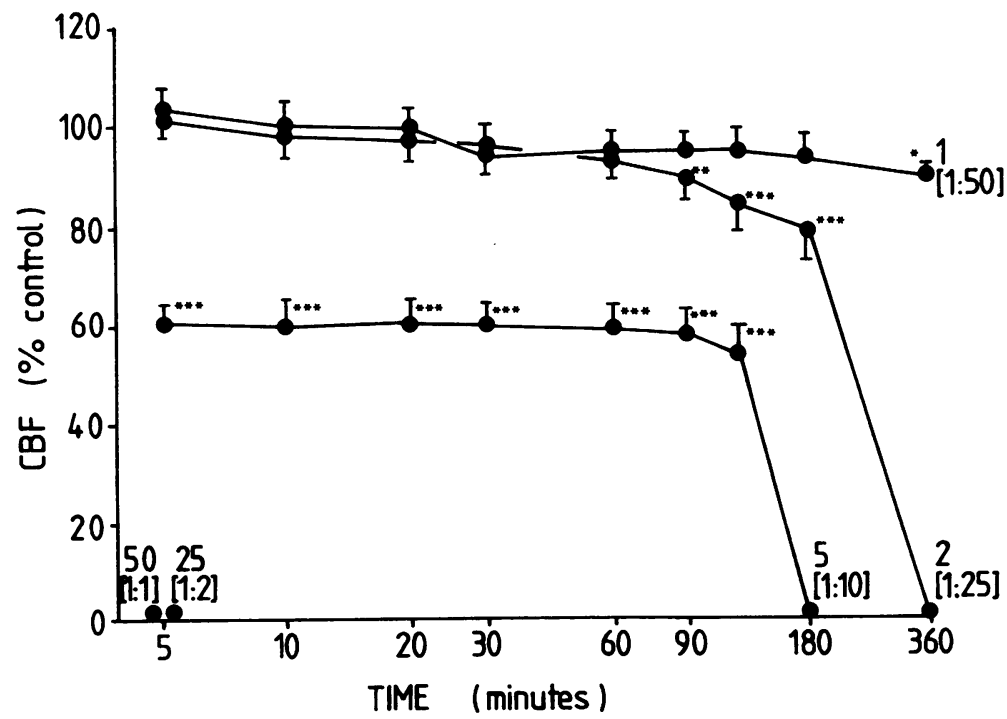

Fig 4 Effect of thiomersal on human nasal ciliary beat frequency $(C B F)$. $\checkmark$ Mean of five experiments standard deviation. The number beside each curve represents the concentration of thiomersal in $\mu \mathrm{g} / \mathrm{ml}$. with the equivalent dilution found in the commercial preparation in brackets. ${ }^{*},{ }^{* *},{ }^{* * *}$ as in figure 1. 
LONG TERM EFFECTS OF BETAMETHASONE AND BETAMETHASONE WITH NEOMYCIN DROPS ON NASAL MUCOCILIARY CLEARANCE

Perennial rhinitis Ten patients reported less nasal obstruction and discharge after betamethasone treatment but 26 did not improve clinically. Two of the 10 responders had a grossly prolonged nasal mucociliary clearance time $(>60 \mathrm{~min})$ before treatment and one of these had a mucociliary clearance time of 20 minutes after treatment. In the remaining eight the mean mucociliary clearance time was $\mathbf{1 3 . 6}$ (4.3) minutes after treatment, which was not significantly shorter than the pretreatment time of 17.8 (6.8) minutes (Mann-Whitney U test).

Of the 26 who failed to respond to treatment, eight had a nasal mucociliary clearance time of over 60 minutes both before and after treatment. In the remaining 18 there was no significant difference (Mann-Whitney $U$ test) between the nasal mucociliary clearance before $(16.1(10.1) \mathrm{min})$ and after (15.9 (8.1) min) treatment.

Chronic sinusitis After treatment with betamethasone with neomycin drops all patients experienced diminution of nasal discharge, change of its colour to white or clear, and less nasal obstruction, although sinus radiographs did not change. Ten of the 40 patients had nasal mucociliary clearance times of over 60 minutes before treatment and in one of them the clearance time fell to 52 minutes after treatment with betamethasone with neomycin drops. In the remaining 30 patients the mean mucociliary clearance time after treatment $(22.0$ (12.0) min) was not significantly different (MannWhitney $U$ test) from that before treatment $(21.3$ (10.9) $\mathrm{min}$ ).

\section{Discussion}

The nasal mucous membranes have an area of 160 $\mathrm{cm}^{2}$ approximately, ${ }^{9}$ the maximum depth of the mucus layer above the tips of the cilia is about 20 $\mu \mathrm{m},{ }^{10}$ and around the cilia the periciliary fluid has a depth of about $5 \mu \mathrm{m}$. On the basis of these figures the volume of secretion in the normal nose can be calculated to be about $0.4 \mathrm{ml}$. The recommended dose for both commercial preparations is two to three drops (about $0.13-0.20 \mathrm{ml}$ ) in each nostril (Glaxo data sheet). Both preparations were ciliotoxic in vitro at a dilution of $1: 2$, which might be expected in the nose immediately after use. In the case of the betamethasone drops the ciliotoxicity was due to the preservative benzalkonium chloride, whereas in the betamethasone with neomycin drops the toxicity was mainly due to the preservative thiomersal with a small contribution from the neomycin. Dilution of the drops in excess of $1: 25$ was required to abrogate these effects.

We found ciliostasis within five minutes with benzalkonium chloride $100 \mu \mathrm{g} / \mathrm{ml}$ and thiomersal 50 $\mu \mathrm{g} / \mathrm{ml}$. Van de Donk et al $^{1}$ found that benzalkonium chloride $100 \mu \mathrm{g} / \mathrm{ml}$ caused a reduction in ciliary beat frequency in chick embryo trachea but no ciliostasis after two hours and that thiomersal $50 \mu \mathrm{g} / \mathrm{ml}$ caused ciliostasis within 40 minutes. Greenwood et al ${ }^{11}$ reported ciliary activity to be present in rabbit nasal epithelium exposed to $500 \mu \mathrm{g} / \mathrm{ml}$ benzalkonium chloride for 60 minutes, but Gallay ${ }^{12}$ saw ciliostasis in guinea pig trachea at a lower concentration (125 $\mu \mathrm{g} / \mathrm{ml}$ ) after 45 minutes. Human nasal cilia would seem therefore to be more sensitive than these animal cilia to the toxic effects of benzalkonium chloride and thiomersal. Van de Donk et $a l^{2}$ reported that the beat frequency of human adenoidal cilia at $25^{\circ} \mathrm{C}$ was reduced to $65 \%$ of the initial value after exposure to benzalkonium chloride 60 $\mu \mathrm{g} / \mathrm{ml}$ with EDTA $1 \mathrm{mg} / \mathrm{ml}$ for 20 minutes. We had similar results using the same concentrations of benzalkonium chloride with EDTA at $25^{\circ} \mathrm{C}$, but at $37^{\circ} \mathrm{C}$ nasal ciliary beat frequency was $50 \%$ of control after five minutes and ciliostasis occurred after 10 minutes. Thus human cilia are more sensitive at $37^{\circ} \mathrm{C}$ than at $25^{\circ} \mathrm{C}$ to the effects of this combination of preservatives.

Van de Donk et al ${ }^{1}$ noted a toxic effect of EDTA on chick embryo tracheal cilia and an additive toxic effect when EDTA was combined with benzalkonium chloride. This effect was probably due to chelation of extracellular calcium. The lack of toxicity of EDTA alone and the lack of enhancement of the toxicity of benzalkonium chloride by EDTA in our human system, even in the presence of calcium free medium, presumably reflects a species difference. These results emphasise that when drug effects on human cilia are investigated cilia from the same species $^{13}$ should be used, at physiological temperature.

Despite the in vitro ciliotoxicity of these preparations we did not observe any significant effect on nasal mucociliary clearance in either the acute or the long term study, or any effect on nasal ciliary beat frequency before and after treatment. This may have been due to dilutional effects of nasal mucus, protection of the cilia by the mucus blanket, or a higher resistance of the cilia in situ. In vitro studies use a relatively mucus depleted preparation of isolated epithelial strips. In a study by Van de Donk et $a l^{3}$ nasal mucociliary clearance (measured by a saccharin and dye method) was prolonged 15 minutes after administration of one drop of a solution containing benzalkonium chloride $60 \mu \mathrm{g} / \mathrm{ml}$ with EDTA $1 \mathrm{mg} / \mathrm{ml}$. In their study, however, the subjects rinsed 
their noses with saline 15 minutes before the initial clearance was measured and 15 minutes before the treatment; thus the nasal mucus could have been diluted or disrupted or both. In our study nasal mucociliary clearance did show a tendency (which failed to reach significance) to quicken in the patients with perennial rhinitis who improved clinically after treatment with betamethasone drops, but it did not change in the patients with chronic sinusitis who improved clinically. This may be due to pathological differences between these conditions rather than any different effect of betamethasone with neomycin drops in the latter group.

In conclusion, betamethasone and betamethasone with neomycin drops are ciliotoxic when ciliated epithelium is exposed to them in vitro, owing to the preservatives benzalkonium chloride and thiomersal. We have, however, found no evidence of in vivo mucociliary dysfunction after acute or long term administration.

PS was supported by Berk Pharmaceuticals Ltd, WG by the Cystic Fibrosis Research Trust, RW by Janssen Pharmaceuticals Ltd, and MG by the Asthma Research Council. This work was financed by the National Fund for Research into Crippling Diseases.

\section{References}

1 Van de Donk JHM, Muller-Plantema IP, Zuidema J, Merkus FWHM. The effects of preservatives on the ciliary beat frequency of chicken embryo tracheas. Rhinology 1980;18:119-33.

2 Van de Donk, Zuidema J, Merkus FWHM. Correla- tion between the sensitivity of the ciliary beat frequency of human adenoidal tissue and chicken embryo tracheas for some drugs. Rhinology 1982;20:81-7.

3 Van de Donk HJM, van den Heuvel AGM, Zuidema J, Merkus FWHM. The effects of nasal drops and their additives on human nasal mucociliary clearance. Rhinology 1982;20:127-37.

4 Stanley PJ, Wilson R, Greenstone MA, Mackay IS, Cole PJ. Abnormal nasal mucociliary clearance in patients with rhinitis and its relationship to concomitant chest disease. Br J Dis Chest 1985;79:77-82.

5 Rutland J, Cole PJ. Non-invasive sampling of nasal cilia for measurement of beat frequency and study of ultrastructure. Lancet 1980;ii:564-5.

6 Andersen I, Camner P, Jensen PL. Nasal clearance in monozygotic twins. Am Rev Respir Dis 1974; 110:301-5.

7 Rutland J, Cole PJ. Nasal mucociliary clearance and ciliary beat frequency in cystic fibrosis compared with sinusitis and bronchiectasis. Thorax 1981;36:654-8.

8 Stanley P, MacWilliam L, Greenstone M, Mackay I, Cole PJ. Efficacy of a saccharin test for screening to detect abnormal mucociliary clearance. $\mathrm{Br} \mathrm{J}$ Dis Chest 1984;78:62-5.

9 Guyton AC. Pulmonary ventilation. In: Textbook of medical physiology. Philadelphia: WB Saunders Company, 1981:476-90.

10 Proctor DF. The mucociliary system. In: Proctor DF, Andersen I, eds. The nose: upper airway physiology and the atmospheric environment. Amsterdam: Elsevier Biomedical Press, 1982:245-78.

11 Greenwood G, Pittenger RE, Constant GA, Ivy AC. Effect of zephiran chloride, tyrothricin, penicillin and streptomycin on ciliary action. Arch Otolaryngol 1946; 43:623-8.

12 Gallay C. Essays physiologique des gouttes nasales. Pharm Acta Helv 1960;35:358-74.

13 Rutland J, Penketh A, Griffin WM, Hodson ME, Batten JC, Cole PJ. Cystic fibrosis serum does not inhibit human ciliary beat frequency. Am Rev Respir Dis 1983;128: 1030-4. 